\title{
IMPACTO POSITIVO DO PCNA-UFPA NO PERFIL ACADÊMICO DOS SEUS MONITORES-VOLUNTÁRIOS
}

Leonardo R. L. Damasceno - leonardo.damasceno@itec.ufpa.br*

Mellina M. Lisboa - mellina.lisboa@itec.ufpa.br*

Lukas R. M. de Sousa - lukas.sousa@itec.ufpa.br*

Thatianne Maria F. Valente - thatiane.valente@ itec.ufpa.br*

Alexandre G. Rodrigues - alexgr@ufpa.br*

Universidade Federal do Pará*

Rua Augusto Corrêa, 01*

66075-110 - Belém - Pará*

Resumo: É evidente a importância da monitoria para o desenvolvimento acadêmico de um estudante de ensino superior, seja do discente assistido ou do facilitador. Essa afirmativa pode ser conferida em iniciativas como o Programa de Cursos de Nivelamento da Aprendizagem (PCNA) da Universidade Federal do Pará (UFPA) - uma proposta voltada à redução dos índices de reprovação e de evasão nos cursos de engenharia. O Programa conta com a contribuição de monitores bolsistas e monitores voluntários para realização de suas atividades, atuando este segundo grupo no auxílio dos bolsistas. Os benefícios provindos dessa atuação são inúmeros, tais como a aquisição de experiências acadêmicas, que estão relacionadas às melhorias de atividades em grupo e na tomada de decisões importantes, por exemplo. Em vista disso, o presente artigo tem como finalidade analisar, por meio de um questionário, a influência do PCNA no perfil acadêmico e na escolha do magistério, como profissão, dos seus voluntários.

Palavras-chave: Atividade Voluntária. Monitor. Monitoria. PCNA. Perfil Acadêmico.

\section{INTRODUÇÃO}

No ensino superior, docentes e discentes entram em contato com os mais variados níveis de capacidade de aprendizado, o que se torna um empecilho para uniformizar uma formação com êxito dos estudantes recém-ingressos. A fim de atenuar este problema, as Universidades têm investido cada vez mais em programas de monitoria, cuja eficácia como processo de ensino-aprendizagem pode ser verificada ao contemplar as dimensões técnica, política e social da prática pedagógica, como afirma Candau (1985).

O protagonista deste processo, o monitor, segundo Abreu e Massetto (1989), é um (a) estudante em processo de formação com capacidade de auxiliar outros estudantes a se desenvolverem em torno do ensino-aprendizagem. É válido ainda destacar que essa inciativa pedagógica também tem se mostrado um importante fator para o desenvolvimento de habilidades do próprio facilitador, seja para a graduação ou para o mercado de trabalho.

Baseando-se nesta proposta de ampliação educacional da sociedade, a Universidade Federal do Pará oferece aos seus estudantes recém-ingressos de engenharia o Programa de Cursos de Nivelamento da Aprendizagem em Ciências Básicas para Engenharias (PCNA), desenvolvido em 2011 pelo Instituto de Tecnologia (ITEC-UFPA) e aprovado pela então Próreitora de Extensão (PROEX) (RODRIGUES et al, 2013), sendo atualmente mantido pela Superintendência de Assistência Estudantil (SAEST). 
O Programa conta com a atuação de monitores bolsistas - normalmente estudantes de engenharia - para sanar dúvidas, ministrar aulas e aplicar pequenos testes sob a orientação da coordenação; além de monitores voluntários, responsáveis por auxiliar os monitores em suas tarefas, sendo peças de extrema ajuda para o desenrolar das atividades do PCNA.

Atentando-se um olhar mais particular ao monitor-voluntário, observa-se que, ao passar pelo estágio de coautor das atividades, a este são possibilitadas também inúmeras experiências de trabalho em equipe, início de um processo de tomada de decisões, e chances de se tornar, num futuro próximo, monitor-bolsista do Programa.

Esses e outros fatores serão analisados e comparados no decorrer desta pesquisa, cuja finalidade consiste em destacar iniciativas e interesses atuais e futuros dos monitoresvoluntários que exerceram e/ou exercem atividade no programa. Como forma de viabilizar o estudo, foram avaliados os dados de um questionário, a fim de compreender a influência das atividades efetuadas durante o nivelamento do PCNA no perfil acadêmico dos voluntários.

\section{REVISÃO BIBLIOGRÁFICA}

\subsection{Benefícios da monitoria ao facilitador}

São recorrentes e expressivas as pesquisas científicas que apontam a importância do sistema de monitoria no ensino superior, principalmente quando se referem às graduações em engenharia (PALHETA et al, 2017). Nesse sentido, vale destacar as mudanças significativas que a monitoria também proporciona ao perfil acadêmico do monitor.

O primeiro benefício é o crescimento intelectual do facilitador, tendo em vista que este necessita desenvolver novos métodos de estudos dos conteúdos a serem trabalhados na monitoria, a fim de beneficiar a aprendizagem dos alunos assistidos. Ou seja, o monitor se reinventa como discente, melhorando seus métodos de estudo e aprendizagem, o que proporciona o aumento do seu conhecimento tanto para ensinar quanto para o seu desempenho acadêmico (SILVEIRA; SALES, 2016).

A autonomia é o segundo benefício adquirido, pois é o monitor que muitas vezes desenvolve o seu próprio planejamento pedagógico da monitoria e seleciona, de forma independente, as informações a serem compartilhadas (SILVEIRA; SALES, 2016). Além disso, essa experiência permite ao aluno compreender a realidade por detrás da profissão de docente, o que desencadeia a valorização do magistério superior, favorecendo uma possível descoberta de vocação profissional (BOTELHO et al, 2019).

\subsection{O PCNA}

O ingresso e a realização de um curso superior em uma instituição pública não podem ser considerados tarefas fáceis, especialmente para estudantes oriundos da rede pública de ensino ou mesmo quilombolas, pela falta de suporte e até mesmo pela concorrência (VASCONCELOS; SILVA, 2005). Nesse sentido, o Programa de Cursos de Nivelamento da Aprendizagem foi pensado como forma de atender a demanda dos calouros de engenharia da Universidade Federal do Pará e mitigar a sua evasão nos primeiros períodos letivos, atuando em quatro eixos básicos: Matemática, Física, Química e Tecnologia Elementares.

O programa oferece, de forma gratuita, cursos de nivelamento das quatro disciplinas mencionadas, com aulas presenciais no turno da manhã e plantões de dúvidas à tarde, durante as três semanas que antecedem o período letivo dos calouros de engenharia. Tais atividades são realizadas por monitores bolsistas com o auxílio de monitores voluntários e a supervisão da coordenação do Programa. Ao final do curso, os alunos ainda recebem certificados de carga 
horária equivalentes ao seu desempenho em cada disciplina, avaliado no decorrer das três semanas por meio de testes, listas de exercícios, dinâmicas de atividades e provas.

Outra vertente em que o PCNA atua é a de pesquisas científicas. Desde a sua origem, o Programa fomenta o desenvolvimento de artigos científicos voltados à educação em engenharia com base nos resultados obtidos a partir das atividades de ensino ofertadas (cursos de nivelamento, monitorias, minicursos e plantões de dúvida), apresentando-os em congressos nacionais e internacionais e capítulos de livros publicados pela ABENGE.

\subsection{Monitor-voluntário do PCNA}

Atuando como ferramenta institucional, o PCNA conta com o apoio de monitores voluntários, discentes da própria Universidade que atuam prontamente e de maneira conjunta aos monitores bolsistas durante os cursos de nivelamento. Os voluntários auxiliam nas aulas, sanando dúvidas dos alunos do Programa, e na correção de atividades. Tal papel é fundamental, na medida em que os próprios monitores também são alunos de graduação. Lidar com turmas de 40 alunos ou mais é um desafio mesmo para professores experientes.

Monitores e voluntários recebem formações distintas, mas complementares. Os voluntários passam por formações que envolvem as coordenações (geral, administrativa e das equipes), onde se destacam os valores do Programa, bem como que deve ser evitado em termos de conduta nas relações com seus colegas monitores e cursistas, deixando-se claro a toda a equipepcna que a mesma é responsável pelo primeiro contato dos alunos recém-chegados com a Universidade.

Sendo um trabalho de responsabilidade, mas sem recebimento de compensação financeira, o PCNA oferece ao aluno que se voluntaria no curso de nivelamento o certificado de carga horária equivalente à sua contribuição ao Programa. No entanto, de maneira mais aprofundada, é possível notar que o voluntário também adquire inúmeros aprendizados úteis para sua graduação e até mesmo para seu futuro profissional, dentre eles: trabalho em equipe, possibilidade de se tornar bolsista do Programa e, ainda, desenvolvimento de interesse na carreira docente.

\section{METODOLOGIA}

\subsection{Método para obtenção de dados}

A fim de validar a proposição objeto desta pesquisa, elaborou-se um questionário na plataforma Google Forms baseado em pesquisas do tipo survey interseccional, onde, em um intervalo definido de tempo, obtiveram-se dados das respostas fornecidas pelo espaço amostral definido para este estudo (BABBIE, 1999), composto por monitores voluntários do PCNA das edições 2019.1, 2019.2 e 2020.1. O convite para participar do questionário foi feito via aplicativo WhatsApp Messenger e e-mail.

Os primeiros dados solicitados aos discentes participantes foram: nome completo, curso da graduação, participação no PCNA como aluno, equipe em que participou como voluntário (Física, Matemática, Química ou TI), edição na qual foi voluntário e o(s) semestre(s) em que participou como monitor voluntário. As demais perguntas se dividiram em três grupos de análise: (1) motivação e autoavaliação de desempenho, (2) experiência e influência acadêmica e (3) perspectiva profissional como docente. A grande maioria das perguntas propostas nestes três blocos foi do tipo objetiva. Há duas questões de respostas abertas. Em uma delas o estudante destaca o desejo de continuar ou não no programa. Na outra, a pergunta final do questionário, o estudante voluntário apresenta sugestões e relato de experiência no programa. Entretanto, tal questão é a única de caráter não obrigatória no instrumento. 


\subsection{Análise 1: Motivação e autoavaliação de desempenho}

A primeira análise consistiu em estudar a motivação do(a) discente para ser monitor(a) voluntário(a) e a autoavaliação de desempenho na sua participação no PCNA. Para compreender a motivação do voluntário envolvido, apresentou-se uma questão objetiva com quatro respostas pré-definidas (o certificado de carga horária, ter participado como aluno, vontade de ser monitor e disposição para ajudar) e uma em aberto, caso as motivações listadas anteriormente não contemplassem suas intenções. Para responder essa pergunta, fora permitido ao aluno escolher, no máximo, três opções.

Por fim, o discente teve que se autoavaliar em sete aspectos (frequência nas aulas, pontualidade, proatividade, cumprimento das tarefas atribuídas pelo monitor, participação em sala, domínio do conteúdo ministrado e estudo prévio do material didático), atribuindo para cada item, um dos seguintes conceitos: insuficiente, razoável, bom e excelente.

\subsection{Análise 2: Experiência e influência acadêmica}

A segunda análise intencionava compreender o quanto a experiência como monitor voluntário do PCNA influenciou a vida acadêmica do discente. Para tal, subdividiu-se essa análise em quatro áreas: continuidade no Programa, acadêmica geral, comunicabilidade e proatividade.

$\mathrm{Na}$ primeira sub-análise, questionou-se quanto ao interesse do discente em continuar no Programa e, em caso afirmativo, de que forma. As respostas foram agrupadas da seguinte forma: monitor, voluntário, monitor ou voluntário e sem intenção.

$\mathrm{Na}$ sub-análise seguinte, objetivando verificar o impacto desta experiência na rotina universitária do discente, inquiriu-se a respeito de seis aspectos definidos: participação em sala de aula, valorização do trabalho do professor, atenção às aulas, assiduidade e pontualidade nas atividades acadêmicas, trabalho em equipe e trabalho com prazos e cumprimento de metas, além de um de manifestação livre (caso a opção desejada não estivesse citada previamente). Nessa etapa, previa-se a possibilidade de assinalar até três aspectos que melhor representassem esse impacto, o que permitiu verificar a existência de alguma relação entre eles.

A terceira sub-análise, com abordagem semelhante à anterior, buscou demonstrar o impacto do PCNA na comunicabilidade do aluno, propondo-se, dessa vez, quatro aspectos: aumento da autoconfiança, perda da timidez, aprimoramento da oratória e dinamismo do discurso, bem como um em aberto. Para essa, fora permitido escolher até duas opções.

Na última sub-análise, foi proposto quesito com a afirmativa de que a participação do aluno como voluntário do PCNA influenciara positivamente na proatividade do mesmo, a fim de que expressasse sua concordância com a afirmativa em uma escala de valores (LIKERT, 1932). A Tabela 1 mostra correlação da resposta e sua interpretação.

Tabela 1 - Correlação entre as opções de resposta e seu significado para a última área da análise 2

\begin{tabular}{c|c}
\hline Significado correspondente & Valor na escala \\
\hline Sem influência & 0 \\
\hline Pouca influência & 1 \\
\hline Muita influência & 2 \\
\hline Total influência & 3 \\
\hline
\end{tabular}

Fonte: Autores

\subsection{Análise 3: Perspectiva profissional como docente}

Por fim, aspirando encontrar uma relação entre a participação como monitor voluntário do PCNA e um futuro na carreira docente, utilizou-se de uma escala para comparar "antes versus 
depois" referente à prioridade da docência na perspectiva profissional do discente. A escala de prioridades variava de 0 a 5 tendo seu correspondente significado detalhado na Tabela 2.

Tabela 2 - Correlação entre as opções de resposta e seu significado para a análise 3

\begin{tabular}{c|c}
\hline Significado correspondente & Valor na escala \\
\hline Sem intenção & 0 \\
\hline Prioridade muito baixa & 1 \\
\hline Prioridade baixa & 2 \\
\hline Prioridade média & 3 \\
\hline Prioridade alta & 4 \\
\hline Prioridade muito alta & 5 \\
\hline
\end{tabular}

Fonte: Autores

A fim de sustentar a hipótese inicial, quantificou-se a variação unitária e percentual neste comparativo do "efeito PCNA" na perspectiva profissional do discente.

\section{RESULTADOS E DISCUSSÃO}

A partir dos dados coletados no questionário, envolvendo 80 participantes, pode-se visualizar o perfil do espaço amostral da pesquisa em questão. Este é majoritariamente $(87,5 \%)$ constituído por discentes dos cursos de Engenharia do Instituto de Tecnologia (ITEC/UFPA), dos quais se destacam as Engenharias Civil (30\%) e Elétrica (24,29\%). Verificou-se, ainda, que mais de $60 \%$ se voluntariaram enquanto estavam no $2^{\circ}$ ou $3^{\circ}$ semestre da graduação e que $81,25 \%$ já foi aluno do Programa. Quanto à distribuição dos voluntários por equipe, esta se deu da seguinte maneira: 41,25\% Matemática, 32,5\% Química, 16,25\% Física e 10\% TI.

\subsection{Análise 1: Motivação e autoavaliação de desempenho}

A principal motivação para se tornar voluntário do PCNA, de acordo com o Gráfico 1, foi a "Disposição para ajudar" (67,50\%), característica almejada explicitamente no perfil do engenheiro egresso segundo as novas diretrizes curriculares (RESOLUÇÃO CNE/CP $\mathrm{N}^{\circ} 2$, 2019). O impacto dessa escolha se dá principalmente na proatividade do discente ao desempenhar as tarefas designadas. Logo em seguida, têm-se "Certificado de carga horária", já esperado em decorrência do cumprimento de um determinado número de horas de extensão ser um dos pré-requisitos para concluir sua graduação. Destaca-se ainda que a participação dos discentes como alunos do Programa foi fundamental para que 53,75\% dos envolvidos ingressassem como voluntários. Observa-se que, por ter sido dada possibilidade de assinalar mais de uma opção, não se garante que essa ordem expresse, rigorosamente, a ordem de prioridade das respostas assinaladas.

Gráfico 1 - Motivação dos discentes para participação voluntária no PCNA $67,50 \%$

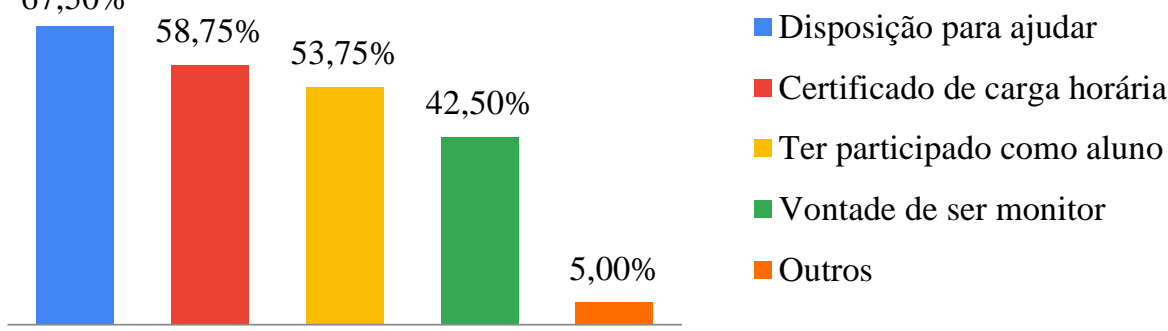

Fonte: Autores 
C COBENCE 2020

"Os desafios para formar hoje o engenheiro do amanhã"
$\mathrm{Ol} \mathrm{a} \mathrm{O3}$ de dezembro Evento On-line

No que diz respeito à autoavaliação de desempenho do discente no Programa, nota-se no Gráfico 2 que todos os aspectos abordados alcançaram mais de 75\% de avaliações positivas ("Bom" ou "Excelente"), salvo "Estudo prévio". Verifica-se também que "Frequência nas aulas" foi o único aspecto em que o conceito "Bom" foi superado por "Excelente" e foi, inclusive, onde este último alcançou o maior percentual. É válido destacar, ainda, o item "Domínio do conteúdo", onde "Bom" e "Excelente" obtiveram maior e menor percentuais, respectivamente, $65 \%$ e 17,5\%. Além disso, em "Estudo prévio" encontrou-se a maior parcela do conceito "Razoável" (29\%).

Gráfico 2 - Autoavaliação de desempenho dos discentes no PCNA

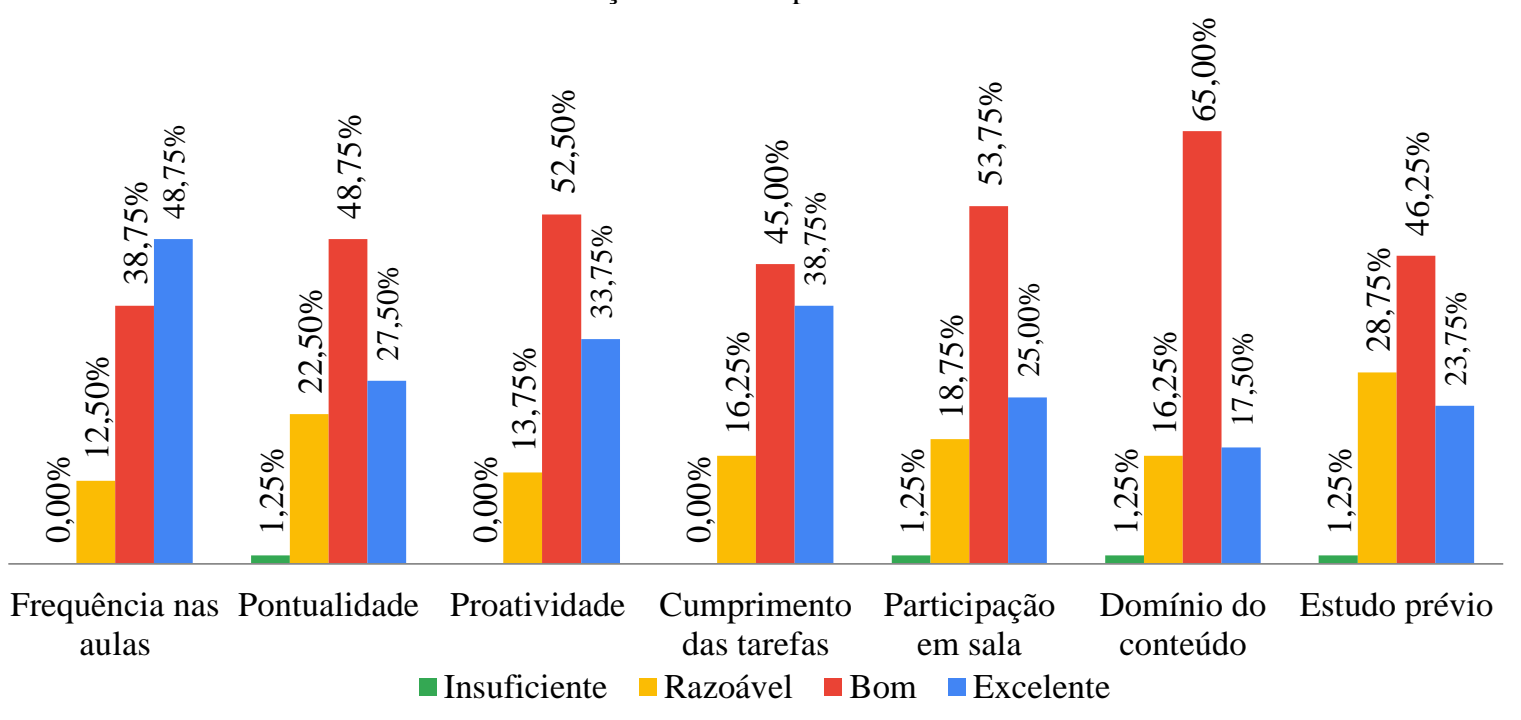

Fonte: Autores

\subsection{Análise 2: Experiência e influência acadêmica}

Dos discentes que participaram do estudo, a grande maioria $(80 \%)$ tem a intenção de permanecer no Programa ajudando de alguma forma, conforme expresso na Tabela 3.

Tabela 3 - Função que o discente deseja exercer no PCNA

\begin{tabular}{c|c}
\hline Valor na escala & Percentual (\%) \\
\hline Monitor & 16,25 \\
\hline Monitor ou Voluntário & 25,00 \\
\hline Voluntário & 33,75 \\
\hline Sem intenção & 20,00 \\
\hline Outros & 5,00 \\
\hline
\end{tabular}

Fonte: Autores

Os dados apresentados na Tabela 3 demonstram a capacidade do PCNA de se renovar e manter sua continuidade ao estimular os novos discentes a se engajarem nas atividades, de modo a garantir o seguimento deste Programa.

Quanto aos que assinalaram a opção "sem intenção", a grande maioria o fez em virtude do seu envolvimento em outras atividades acadêmicas na universidade.

Em seguida, ao analisar os aspectos com maior influência do PCNA na rotina universitária do discente, observou-se que três critérios (Participação em sala de aula, Trabalho em equipe e 
Valorização do trabalho do professor) foram assinalados por pelo menos metade dos estudantes $(56,25 \%, 52,5 \%$ e $50 \%$ respectivamente), como apresentado no Gráfico 3.

Gráfico 3 - Influência positiva do PCNA na realidade acadêmica do discente voluntário no PCNA

\section{$56,25 \%$}

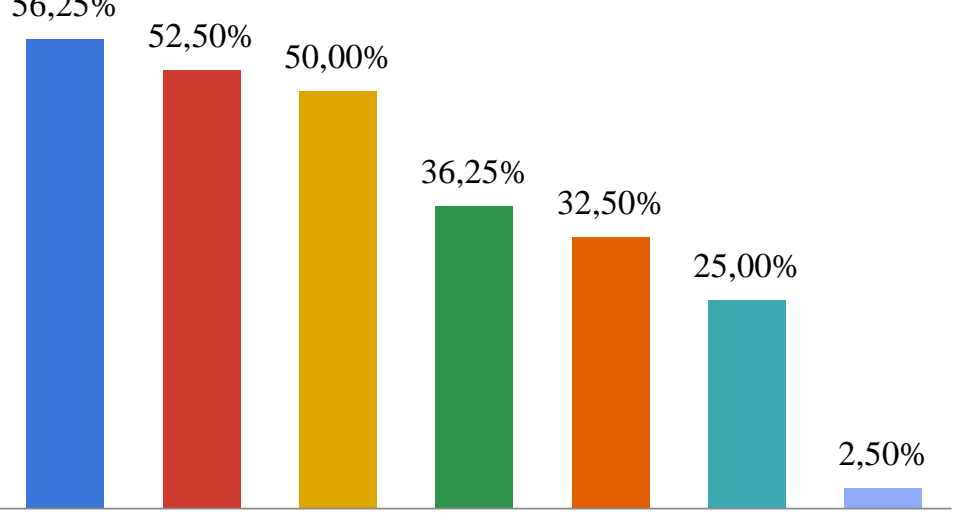

- Participação em sala de aula

- Trabalho em equipe

Valorização do trabalho do professor

Trabalho com prazos e cumprimento de metas

- Atenção às aulas

- Assiduidade e pontualidade nas atividades acadêmicas - Outros

Fonte: Autores

Por haver a possibilidade de serem assinalados até 3 aspectos, analisou-se também a existência de algum vínculo entre as opções escolhidas. Dentre os discentes que escolheram "Valorização do trabalho do professor", mais de $82 \%$ também optaram por outras duas, sendo estas "Participação em sala de aula" e "Trabalho em equipe" (ambas com 47,5\%). As duas primeiras apresentam ligação direta, porém a última foi um resultado inesperado. Dos 32,5\% que assinalaram "Atenção às aulas", 81\% selecionaram outras duas opções, das quais, "Valorização do trabalho do professor" (57,69\%) e "Participação em sala de aula" (46,15\%). Por fim, dos que escolheram "Trabalho com prazos e cumprimentos de metas", quase $60 \%$ também optaram por “Trabalho em equipe”. Nessas três análises específicas, pode-se observar uma relação entre aspectos acadêmicos nas duas primeiras e profissionais na última.

Semelhantemente à análise anterior, o Gráfico 4 expressa a influência do PCNA na comunicabilidade do discente. Nele, visualizou-se que o "Aprimoramento da oratória" foi o aspecto mais positivamente influenciado (60\%) pela participação no Programa.

Gráfico 4 - Influência positiva do PCNA na comunicabilidade do discente voluntário no PCNA

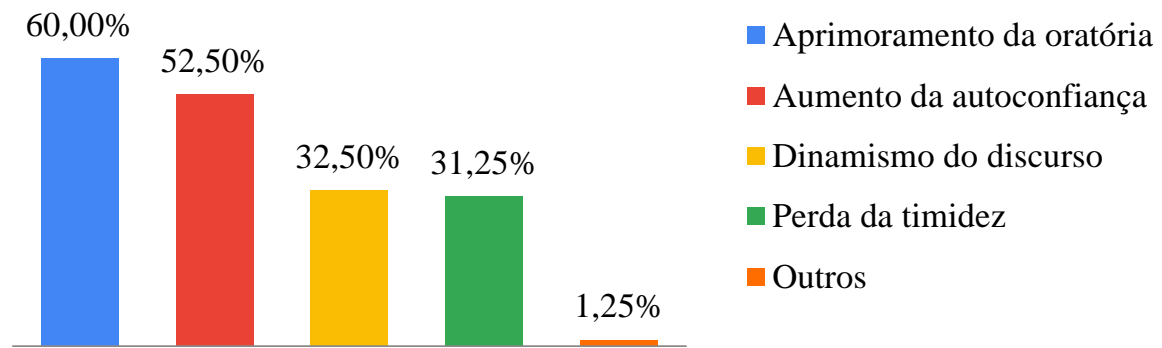

Fonte: Autores

Dos que assinalaram a oratória como um dos aspectos mais aprimorados pela sua participação, $87,5 \%$ também obtiveram melhora em algum outro aspecto da sua comunicabilidade, como: "Aumento da autoconfiança" (42\%) ou "Dinamismo do discurso" (33\%). Dos que escolheram "Perda da timidez", quase 50\% também selecionaram "Aumento da autoconfiança". Quanto às combinações de aspectos marcados, 25\% destas foram "Aumento 
da autoconfiança e Aprimoramento da oratória" e 20\%, "Aprimoramento da oratória e Dinamismo do discurso". Essa influência era esperada e foi comprovada, visto que tais aspectos estão frequentemente presentes na rotina do monitor voluntário do PCNA.

No dia a dia do Programa, para que todos os objetivos (suporte dos discente, produção e correção de testes avaliativos e listas de exercício) sejam cumpridos, requer-se do monitor voluntário que este seja proativo. Nesse sentido, a Tabela 4 evidencia que a dinâmica do PCNA influenciou de forma extremamente positiva no desenvolvimento da proatividade dos discentes, dado que 95\% destes assinalaram "Total influência" ou "Muita influência".

\begin{tabular}{c|c}
\multicolumn{2}{c}{ Tabela 4 - Influência do PCNA na proatividade do discente } \\
\hline Nível de Influência & Percentual (\%) \\
\hline Total Influência & 47,50 \\
\hline Muita Influência & 47,50 \\
\hline Pouca Influência & 3,75 \\
\hline Sem Influência & 1,25 \\
\hline
\end{tabular}

Fonte: Autores

\subsection{Análise 3: Perspectiva profissional como docente}

O Gráfico 5 a seguir apresenta o comparativo da perspectiva profissional do discente como docente prévia e posteriormente à participação no PCNA. Antes, a prioridade profissional apresentava níveis altamente desfavoráveis ou pouco favoráveis ao magistério, onde estavam concentradas $60 \%$ das opiniões. Proporcionalmente ao total, mais de um quarto dos participantes não apresentava qualquer interesse neste futuro profissional.

Gráfico 5 - Comparativo da docência como perspectiva profissional antes versus depois PCNA

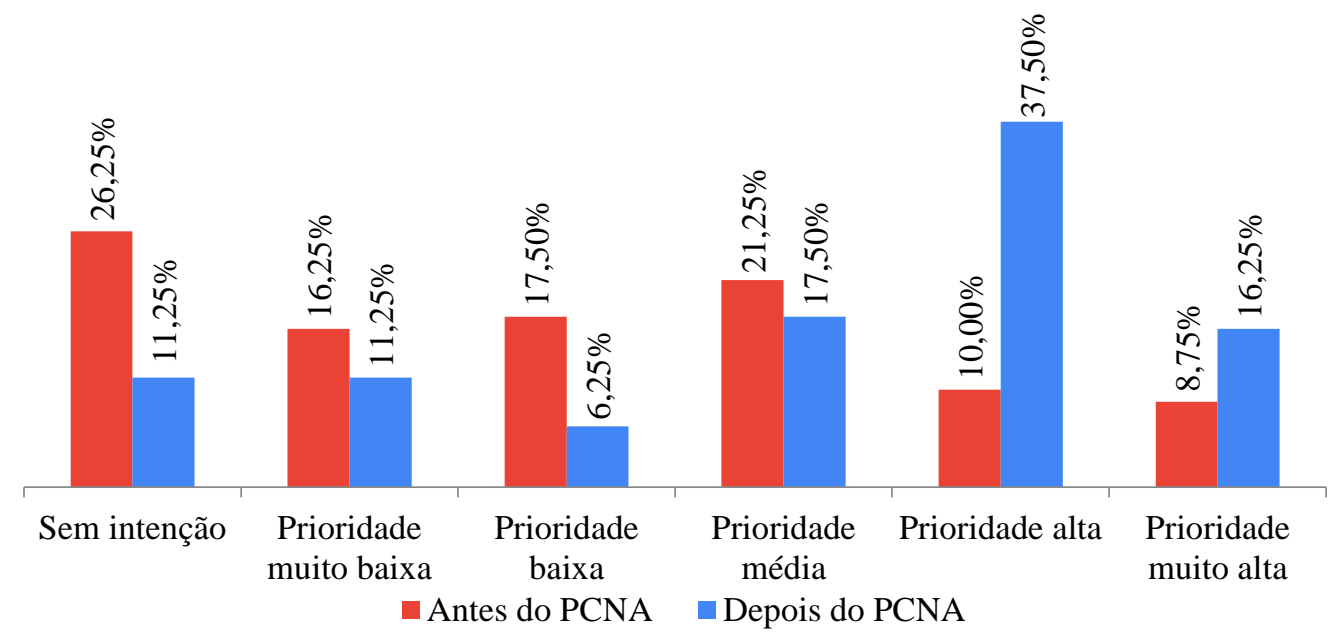

Fonte: Autores

Nota-se, no entanto, uma evidente mudança da expectativa profissional do discente após participar do Programa como voluntário. Pode-se observar uma queda significativa dos que assinalaram "Prioridade baixa" (-64,29\%), "Prioridade muito baixa" (-30,77\%) e "Sem intenção" (-57,14\%). Em contrapartida, muitos passaram a priorizar este futuro profissional, tendo em vista o aumento expressivo dos que assinalaram a opção "Prioridade alta", que registrou crescimento de quase $300 \%$. Além deste, observou-se um acréscimo por volta de $86 \%$ dos que consideram a docência como mais alta prioridade no seu futuro profissional. 
De forma geral, isto indica a capacidade do PCNA de despertar, ou mesmo confirmar, o interesse dos seus voluntários em acolher a docência como futura opção profissional. Tal efeito era previsto, considerando a participação em atividades que têm forte relação com a realidade docente, tais como: planejar e ministrar aulas, sanar dúvidas, prestar esclarecimentos de conteúdo em sala, corrigir testes avaliativos e listas semanais, etc; além da influência que este ambiente de trabalho exerce na valorização do magistério, conforme analisado previamente.

\section{CONSIDERAÇÕES FINAIS}

Ao longo de sua jornada como voluntário do PCNA, este experimenta diversas oportunidades para desenvolver suas competências, tendo em vista o aspecto formativo e engajador do Programa. Tais benefícios são muito bem expressos pelos resultados e discussões deste trabalho, ao mostrarem que, para estes discentes, o PCNA não representa apenas uma oportunidade de creditar horas de extensão - o que já demonstra uma responsabilidade com a integralização curricular da sua graduação -, mas também uma fonte de conhecimento e de valores acadêmicos e profissionais.

Torna-se evidente, a partir de então, o impacto deste programa sobre realidades muito particulares ao discente de engenharia, como trabalho em equipe, proatividade e comunicabilidade, essenciais ao seu crescimento como universitário e, futuramente, à sua afirmação como profissional no mercado. Outro benefício garantido ao voluntário do PCNA é a capacidade de enxergar novos caminhos, outras possibilidades, leia-se carreira acadêmica, como opções de futuro profissional.

Por fim, no intuito de aprofundar os estudos realizados no presente artigo, sugere-se uma análise mais aprofundada de questões específicas, como o impacto do PCNA na escolha dos seus voluntários pela carreira docente como prioridade na perspectiva profissional.

\section{Agradecimentos}

Os autores agradecem à Superintendência de Assistência Estudantil (SAEST) da UFPA pelo incondicional apoio financeiro a este programa. Também agradecem a colaboração dos professores Msc. José Benício da Cruz Costa e Dra. Shirley Cristina Cabral Nascimento.

\section{REFERENCIAS}

ABREU, M. C. de; MASETTO, M.T. O professor universitário em sala de aula. São Paulo: Associados, 1989.

BABBIE, Earl. Métodos de Pesquisas de Survey. Tradução Guilherme Cezarino. Belo Horizonte: Ed. UFMG, 1999, p. 519.

BOTELHO, L. V.; LOURENÇO, A. E. P.; LACERDA, M. G. DE; WOLLZ, L. E. B. Academic monitorship and professional training in health: an integrative review. ABCS Health Sciences, v. 44, n. 1, 30 Apr. 2019.

BRASIL CNE. Conselho Nacional de Educação. Resolução da Câmara de Educação Superior - CES No 2, 24/04/2019. Diretrizes Curriculares Nacionais do Curso de Graduação em Engenharia - Abril, 2019

CANDAU, Vera Maria. A didática e a formação de educadores - da exaltação à negação: a busca da relevância. In: A didática em questão. 36. ed. Petrópolis: Vozes, 2014. cap. 1, p. 1324 
LIKERT, R. A technique for the measurement of attitudes. Archives in Psychology, 140, p. $1-55,1932$

PALHETA, Fernanda L.; LISBOA, Mellina M.; OLIVEIRA, João M. C. de; RODRIGUES, Alexandre. G.; COSTA, Benício C.; LOPES, Alessandra M. S. Aplicação de uma atividade de monitoria em uma disciplina de cálculo. In: XLV Congresso Brasileiro de Educação em Engenharia, 2017, Santa Catarina. Anais. Joinville, 2017.

RODRIGUES, Alexandre. G.; FONSECA Maria C. P.; SOARES, Rosana P. O.; NASCIMENTO, Shirley C. C.; COSTA, José B. C. A utilização do uso de novas tecnologias no ensino de ciências básicas para engenharia: estudo de caso em um projeto de nivelamento. In: XLI - Congresso Brasileiro de Ensino de Engenharia, 2013, Rio Grande do Sul. Gramado. Anais. Gramado, 2013.

SILVEIRA, E.; SALES, F. A importância do Programa de Monitoria no ensino de Biblioteconomia da Universidade do Estado de Santa Catarina (UDESC). InCID: Revista de Ciência da Informação e Documentação, v. 7, n. 1, p. 131-149, 5 abr. 2016.

VASCONCELOS, S.D; SILVA, E.G. Acesso à Universidade Pública Através de Cotas: uma reflexão a partir da percepção de alunos de um pré-vestibular inclusivo. Centro de Ciências Biológicas - UFPE, 2005.

\title{
POSITIVE IMPACT OF PCNA-UFPA IN THE ACADEMIC PROFILE OF ITS VOLUNTEER MONITORS
}

\begin{abstract}
It is evident the importance of monitoring for the academic development of a higher education student, either the assisted student or the facilitator. This statement can be checked in initiatives such as the Learning Leveling Course Program (PCNA) at the Federal University of Pará (UFPA) - a proposal aimed at reducing failure and evasion rates in engineering courses. The Program counts on scholarship monitors and volunteer monitors contribution to carry out its activities, in which this second group acts to assist the scholarship holders. The benefits resulting from this performance are numerous, such as the acquisition of academic experiences, which are related to the improvement of group activities and important decisionmaking, for example. In view of this, this article aims to analyze, by means of a questionnaire, the influence of PCNA on its volunteers academic profile and on choosing teaching as a profession.
\end{abstract}

Keywords: Voluntary Activity. Monitor. Monitoring. PCNA. Academic Profile. 